\title{
Performance Evaluation of a Pulse Detonation Engine Using Vortex Generators as Obstacles in the Combustion Chamber
}

\section{Mukesh Yadav ( $\square$ mukesh7541@gmail.com )}

Department of Mechanical Engineering, Delhi Technological University, Delhi 110042, India https://orcid.org/0000-0003-2199-3921

Avhishek Jha

Delhi Technological University

\section{Manish Bista}

Delhi Technological University

\section{BB Arora}

Delhi Technological University

\section{Research}

Keywords: Pulse Detonation Engine, Ansys Fluent, DDT, Supersonic combustion

Posted Date: September 30th, 2020

DOI: https://doi.org/10.21203/rs.3.rs-81993/v1

License: (c) (i) This work is licensed under a Creative Commons Attribution 4.0 International License. Read Full License 


\section{Abstract}

Propulsion based engines have been known for their exemplary thrust but also for lower fuel efficiency and speed of operation which is limited to subsonic and the level of intermittent vibrations produced. Pulse Detonation Engine (PDE) is similar to a Pulse Jet Engine (PJE) except for the fact that the flame formed inside the combustion chamber of PDE travels at supersonic speed, whereas in PJE, it is subsonic. The supersonic speed of flame front in PDE is because of the detonation wave formed during the combustion of the fuel mixture which is in the order of $2000 \mathrm{~m} / \mathrm{s}$ and is based on constant volume combustion. A process called Deflagration to Detonation Transition (DDT) can be used for which turbulence has to be created inside the combustion chamber. The obstacles used in this study were vortex generators and the CAD model of the engine and the obstacles assembly was made in SOLIDWORKS 19.0 software. ANSYS (FLUENT) 16.0 was used for the simulation of the combustion inside the combustion chamber using the Species Transport Model for the performance evaluation.

\section{Full Text}

This preprint is available for download as a PDF.

\section{Tables}

Due to technical limitations, table 1-4 is only available as a download in the Supplemental Files section.

\section{Figures}

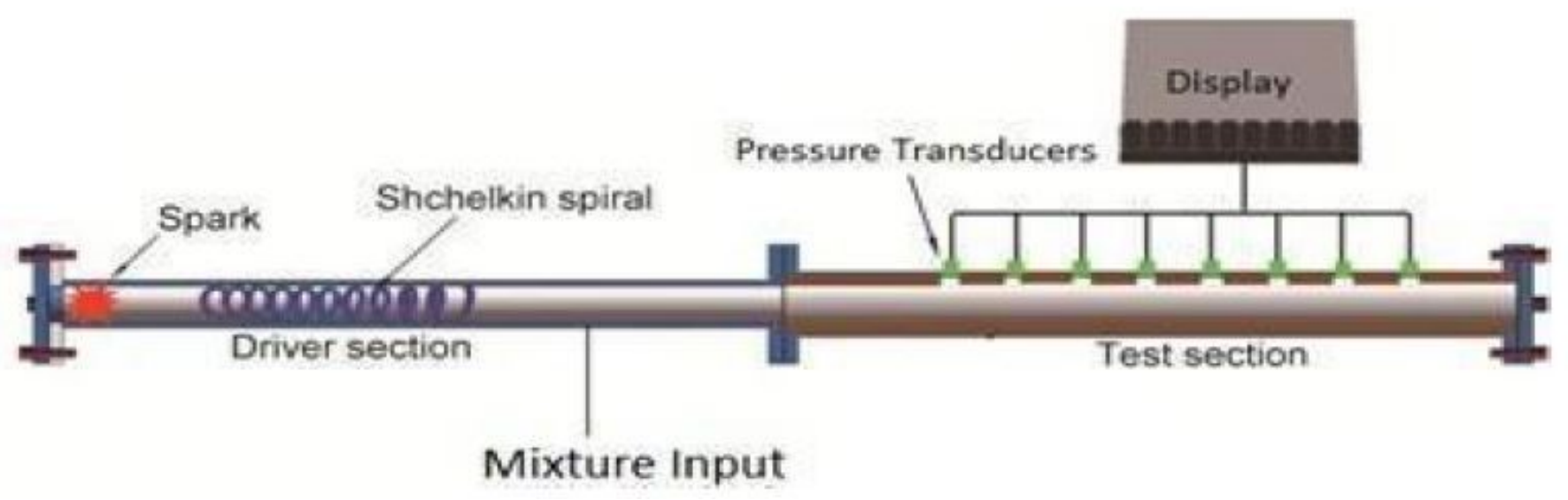

Figure 1

General PDE experimental setup with Shchelkin spiral [12] 


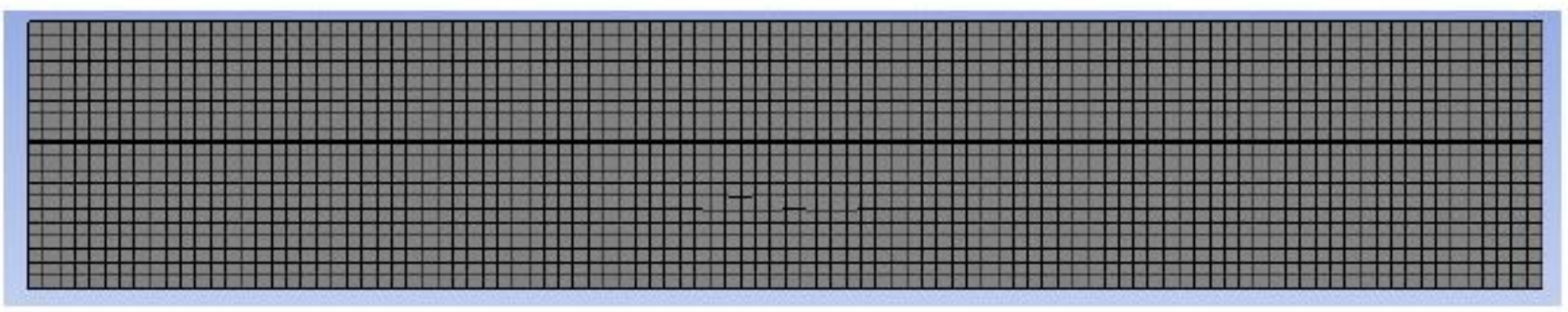

Figure 2

A two-dimensional mesh of an ideal PDE tube
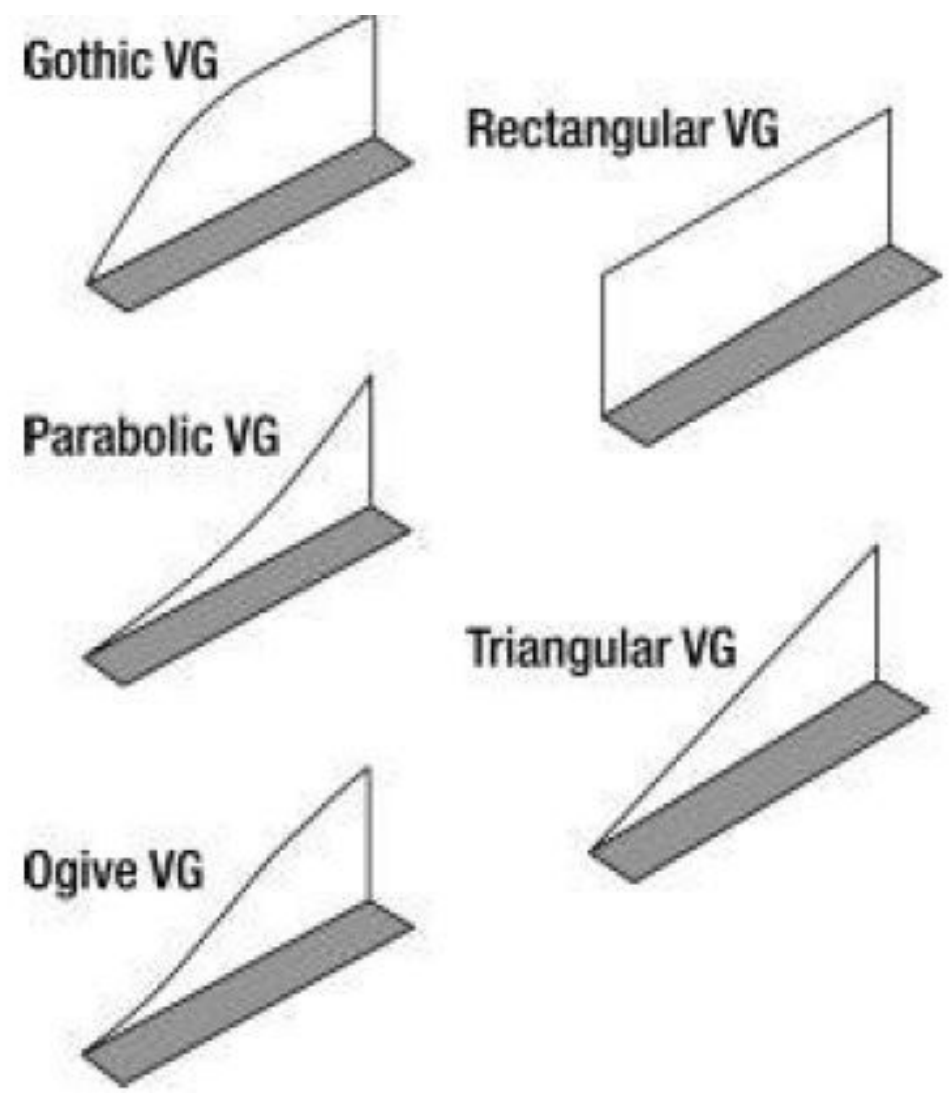

Figure 3

Various shapes of vortex generators.

$$
\begin{array}{llc} 
& \multicolumn{1}{c}{\text { Variable Meaning }} & \text { Value at Sea Level } \\
\cline { 2 - 3 } R e=\frac{\rho V x}{\mu} & \rho \text { Air density }[\mathrm{kg} / \mathrm{m} 3] & 1.205 \\
\mathrm{~V} & =\text { Stall speed }[\mathrm{m} / \mathrm{s}] & - \\
x & =\text { Chord length }[\mathrm{m}] & - \\
\mu & =\text { dynamic viscosity }[\mathrm{kg} / \mathrm{m}-\mathrm{s}] & 1.983^{*} 10^{\wedge}-5
\end{array}
$$

Figure 4 
The equation for the Reynolds Number Calculation

\section{CAD MODELS}
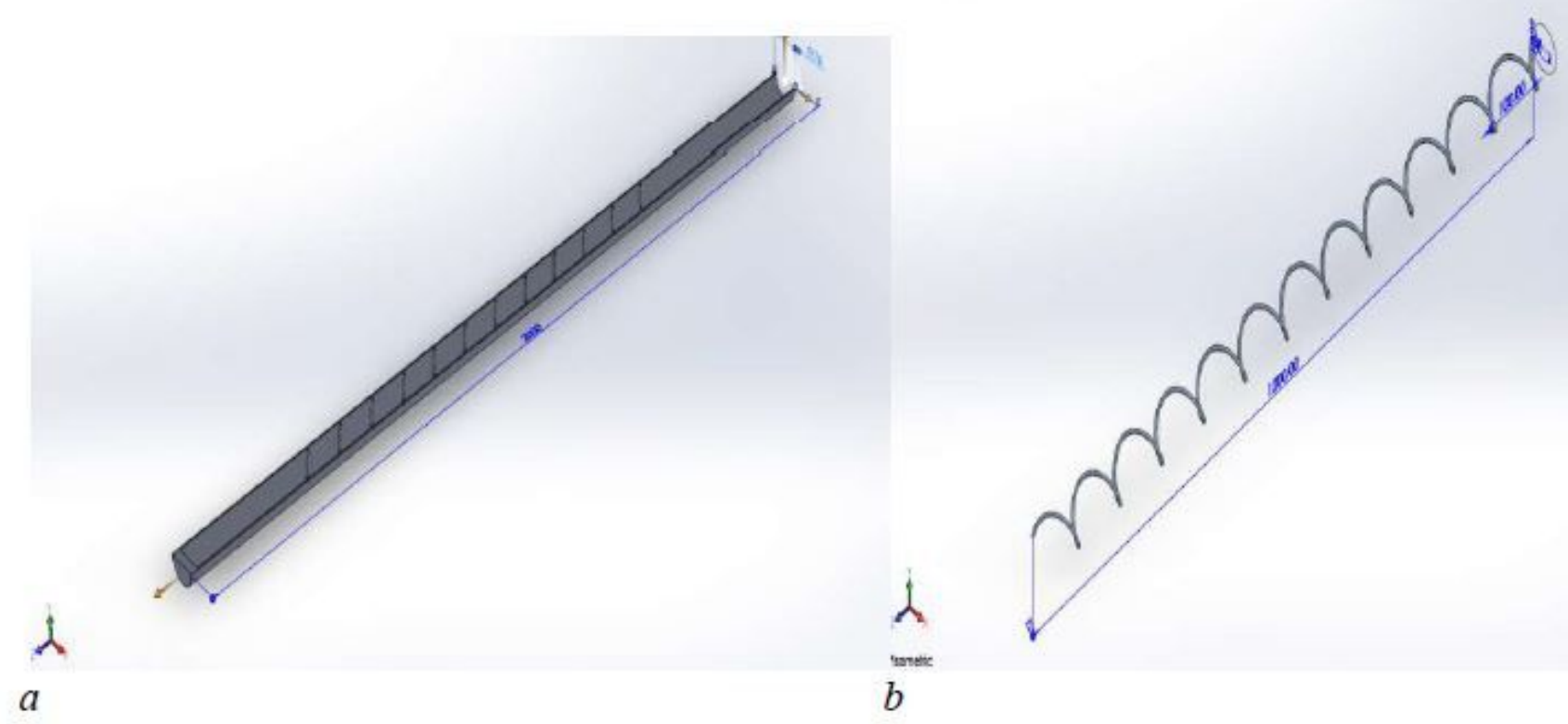

Figure 5

(a) Isometric View of the combustion chamber with Shchelkin Spiral (b) Isometric View of Shchelkin Spiral
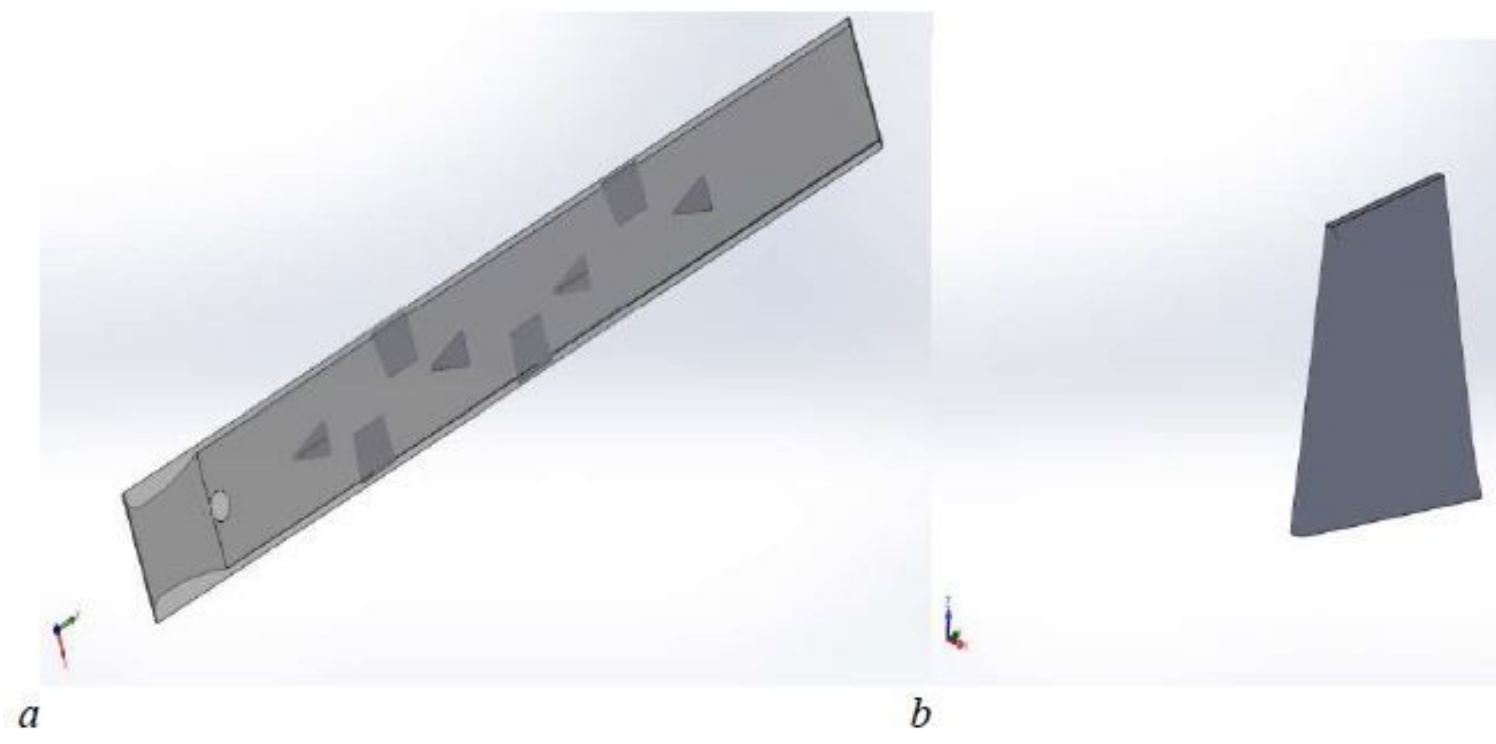

Figure 6

(a) Isometric View of PDE with Vortex Generator; (b) Isometric view of Vortex generator 


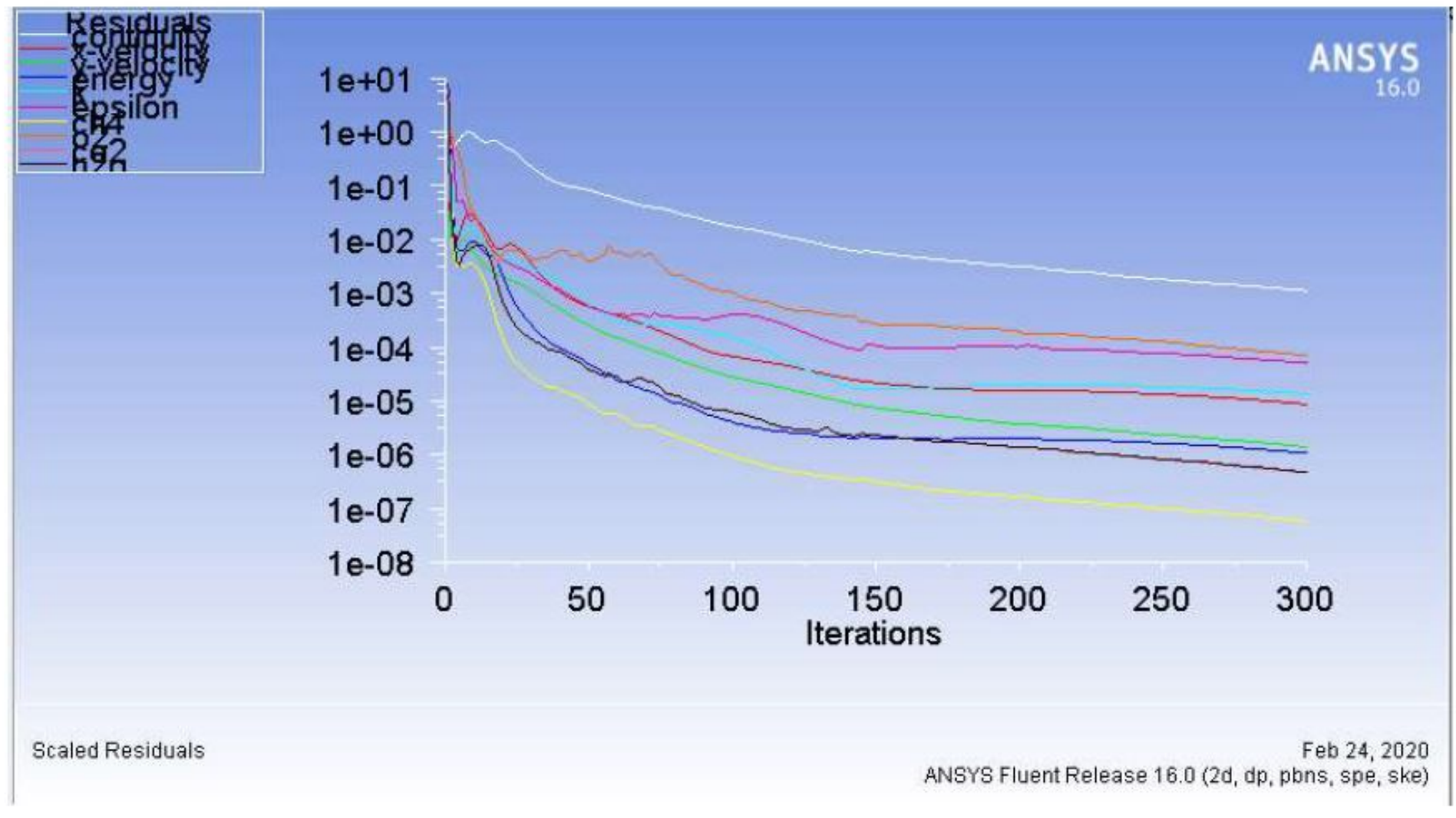

Figure 7

Total number of Iterations

\section{PRESSURE}

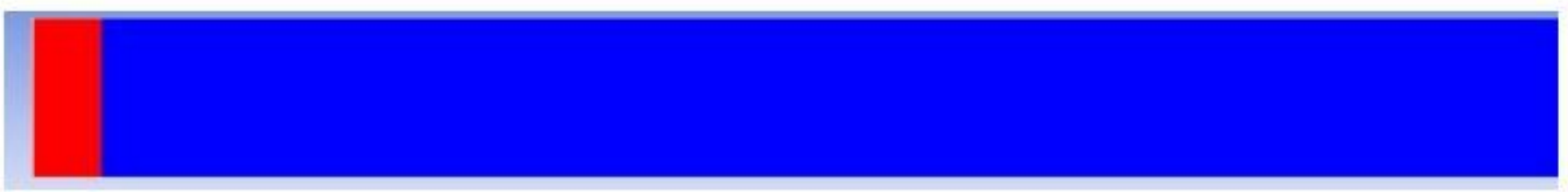

Figure 8

Initial conditions for the ideal PDE tube with pressure contour 


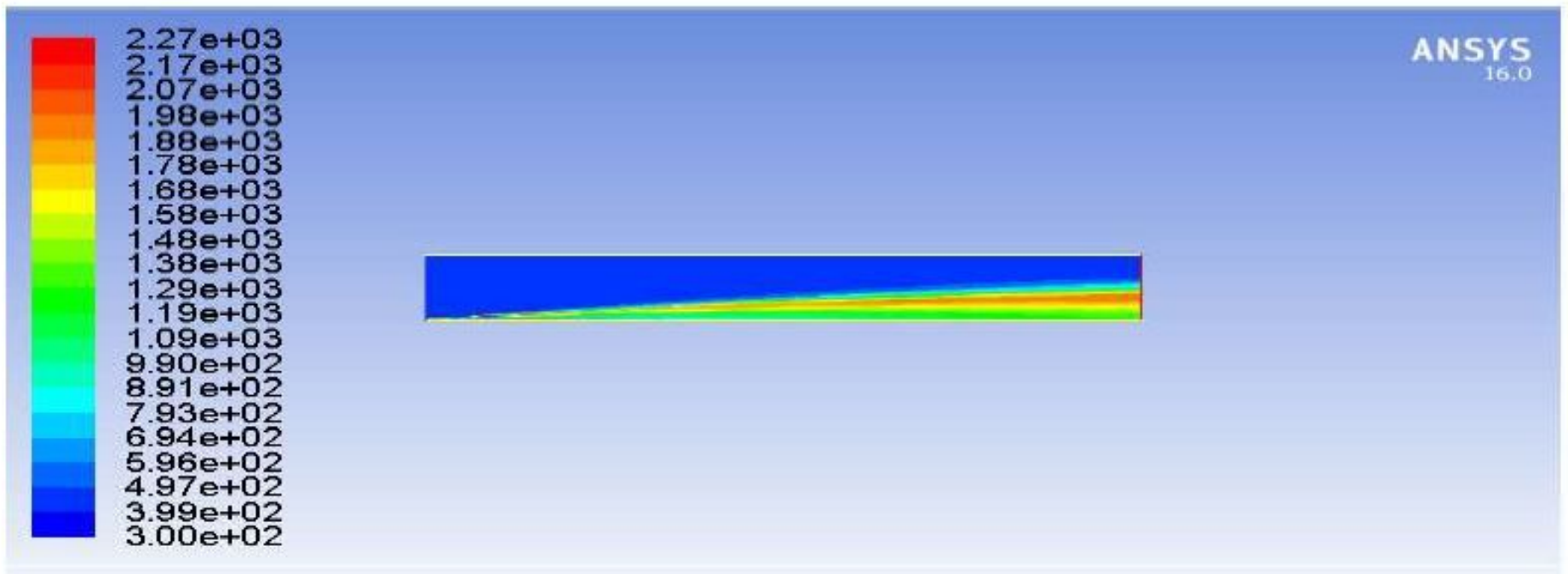

Pronles of Static Temperature (k)

Feb 24, 2020 ANSYS Fluentrelease 16.0 ( $2 \mathrm{~d}, \mathrm{ap}, \mathrm{pbns}, \mathrm{spe}, \mathrm{ske})$

\section{Figure 9}

ZND Temperature profile

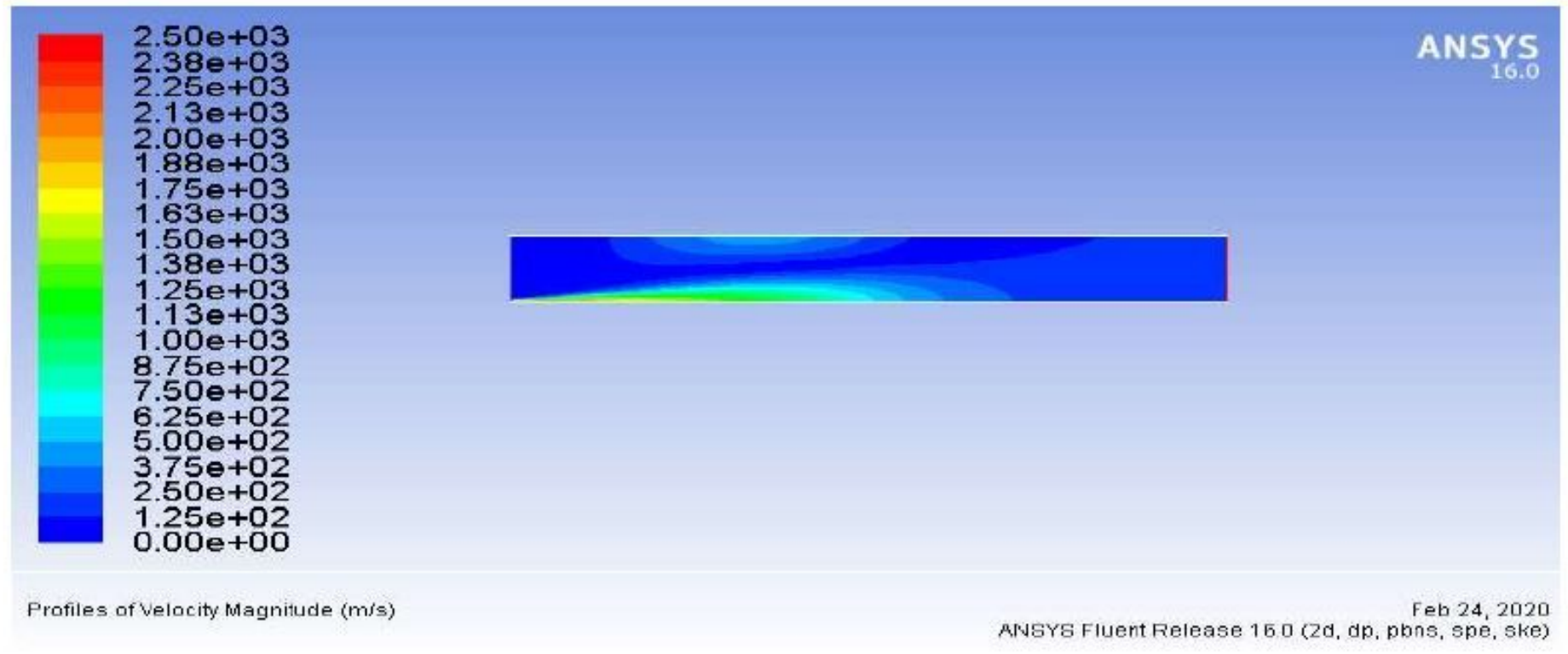

Figure 10

Wave velocity profile 


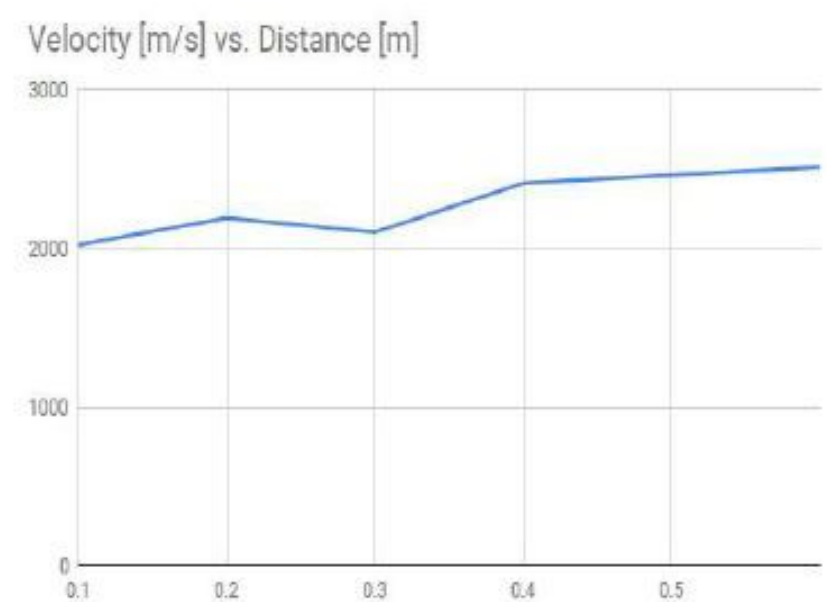

a

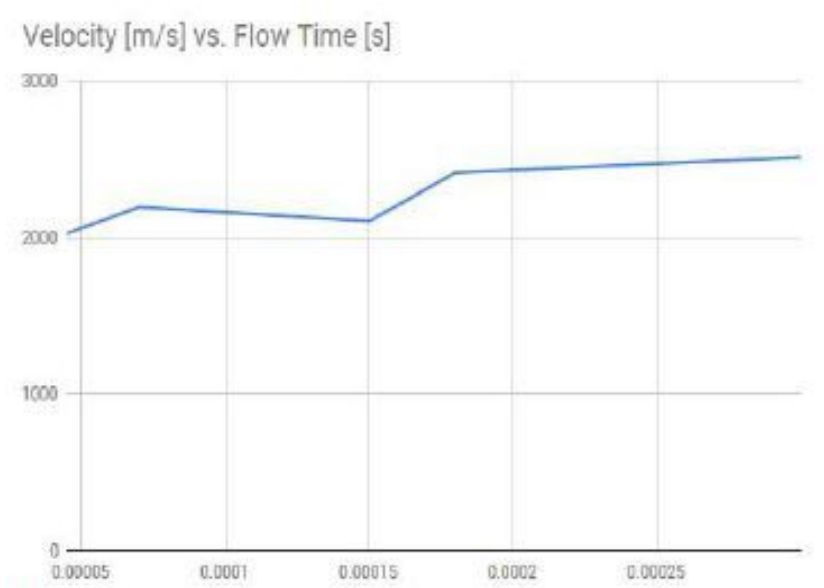

b

\section{Figure 11}

Figure12(a). Change of velocity wrt time 12(b) Change of velocity wrt tube length

\section{Supplementary Files}

This is a list of supplementary files associated with this preprint. Click to download.

- tables.pdf 